\title{
EVALUASI KINERJA STRUKTUR DUAL SYSTEM DENGAN BELT TRUSS
}

\author{
Dwi Prasetyo Utomo ${ }^{1}$, Roesdiman Soegiarso² \\ ${ }^{1}$ Magister Teknik Sipil, Universitas Tarumanagara Jakarta \\ Email:Prhasetyo@gmail.com \\ ${ }^{2}$ Magister Teknik Sipil, Universitas Tarumanagara Jakarta \\ Email: roesdimans@pps.untar.ac.id
}

\begin{abstract}
ABSTRAK
Dalam aplikasi rekayasa struktur gedung, batasan defleksi bangunan atau interstory drift adalah masalah penting. Pada bangunan tinggi yang lebih dari atau sama dengan 60 lantai pada era sekarang sudah menggunakan sistem pada struktur bangunan tersebut. Fungsi dari Belt Truss tersebut berguna untuk mengurangi defleksi yang terjadi pada bangunan dengan mengkonvesi momen guling bangunan menjadi gaya aksial kolom eksterior. Struktur Belt Truss sendiri materialnya bisa menggunakan struktur beton bertulang dan struktur baja. Karena struktur Belt Truss merupakan inovasi pada dunia rekayasa struktur, maka nilai parameter beban gempa tidak tercantum pada Standar Peraturan Perencanaan Bangunan yang berlaku. Standart Peraturan Bangunan tahan gempa diperlukan parameter parameter Faktor Modifikasi Respon (R), Faktor Kuat Lebih $(\Omega o)$, dan Perbesaran Defleksi $(\mathrm{Cd})$ untuk penentuan beban gempa. Dikarenakan parameter pada struktur Belt Truss tidak tercantum pada Standar Peraturan Bangunan Tahan Gempa, maka dilakukan penelitian parameter-parameter beban gempa pada struktur Belt Truss tersebut. Metode yang digunakan dalam penelitian ini adalah studi literatur dengan menggunakan analisa Beban Dorong Pushover Analysis sesuai ATC - 40 dan FEMA 356.
\end{abstract}

Kata Kunci: Belt Truss; Dual System; ATC - 40; FEMA 356; Faktor Modifikasi Respon (R); Faktor Kuat Lebih $(\Omega \mathrm{o})$; dan Perbesaran Defleksi $(\mathrm{Cd})$

\begin{abstract}
In structural engineering applications, the limit of building deflection or interstory drift is an important issue. In highrise buildings that are more than or equal to 60 floors in the current era, systems are used in the structure of the building. The function of the Belt Truss is to reduce the deflection that occurs in the building by converting the building's overturning moment into the axial force of the exterior column. The Belt Truss structure itself can use reinforced concrete structures and steel structures. Because the Belt Truss structure is an innovation in the world of structural engineering, the parameter values for earthquake loads are not listed in the applicable Building Planning Standards. The standard for earthquake-resistant building regulations requires the parameters of Response Modification Factor (R), Overstrength Factor ( $\Omega$ o), and Deflection Magnification $(C d)$ for determining earthquake loads. Because the parameters on the Belt Truss structure are not listed in the Standard for Earthquake Resistant Building Regulations, a study of the earthquake load parameters on the Belt Truss structure was carried out. The method used in this research is a literature study using Pushover Load Analysis according to ATC - 40 and FEMA 356.
\end{abstract}

Keywords: Belt Truss, Dual System; ATC - 40; FEMA 356; Response Modification Factor (R); Overstrength Factor $(\Omega o) ;$ and Deflection Magnification $(\mathrm{Cd})$

\section{PENDAHULUAN}

\section{Latar Belakang}

Perencanaan bangunan tinggi di Indonesia diperlukan sebuah perencanaan yang tahan terhadap beban gempa, sehingga tidak terjadi adanya korban jiwa yang diakibatkan kegagalan struktur bangunan pada saat terjadi gempa. Sistem struktur bangunan tinggi dengan jumlah lantai kurang dari 40 lantai paling efektif menggunakan struktur menggunakan struktur dual system (shear wall dan special momen frame). Sedangkan bangunan yang melebihi 40 lantai apabila tetap 
menggunakan dual system maka defleksi lateral akan sangat besar sehingga tidak memenuhi syarat ASCE 7-16. Untuk mengatasi defleksi lateral yang sangat besar tersebut yaitu dengan menambahkan struktur Belt Truss pada bangunan tersebut sebagai virtual Outrigger.

Menurut Nair (1998) bahwa vitual Outrigger pada bangunan 77 lantai yang dibentuk dari shearwall-Belt Truss ternyata dapat mereduksi simpangan lateral pada bangunan dengan baik. Menurut Fawzia and Fatima (2010) dengan menggunakan sistem Outrigger dan Belt Truss dapat mereduksi interstorey drift atau simpangan lateral sekitar 8\% - 9\%. Menurut Faimun, Tavio dan Kurnianto (2017) penggunaan sistem Outrigger dan Belt Truss dapat mengurangi simpangan antar lantai pada struktur dual system bangunan gedung Apartemen Gunawangsa Tidar Surabaya. Perbandingan defleksi lateral pada gedung Apartemen Gunawangsa Tidar Surabaya.

Dalam segi desain struktur bangunan, standar pembeban ASCE 7-16 tabel 12.2-1 tidak menyebutkan secara spesifik nilai faktor modifikasi respons (R) untuk mendesain beban gempa pada struktur dengan adanya penambahan Belt Truss. Sehingga didapat hasil desain yang baik dan benar sesuai syarat ASCE 7-16 dan ACI 318 - 14.

\section{Rumusan Masalah}

Berdasarkan latar belakang yang telah dikemukakan. Maka masalah yang timbul adalah bagaimana Kinerja Struktur Dual System dengan Belt Truss dan nilai parameter - parameter perencanaan struktur tahan gempa meliputi Faktor Modifikasi Respon (R), Faktor Perbesaran Defleksi (Cd), dan Faktor Kuat Lebih Struktur $(\Omega o)$.

\section{METODE PENELITIAN}

Penelitian dilakukan dengan studi literatur textbook, artikel, jurnal, ensiklopedi, dan sumber lain. Bangunan yang di tinjau adalah bangunan dengan jumlah lantai 60 lantai dengan Denah Bangunan (dimensi struktur sama pada semua tinjauan Belt Truss) dapat dilihat pada Gambar 2a. Jumlah Belt Truss yang di tinjau adalah 1 Belt Truss sampai 4 Belt Truss dengan penempatan Belt Truss paling optimum menurut Krunal Z. Mistry et al. (2015) dapat dilihat pada Gambar 2b. Alur penelitian ditampilkan dalam bagan alir kerja (flow chart) sebagai berikut:

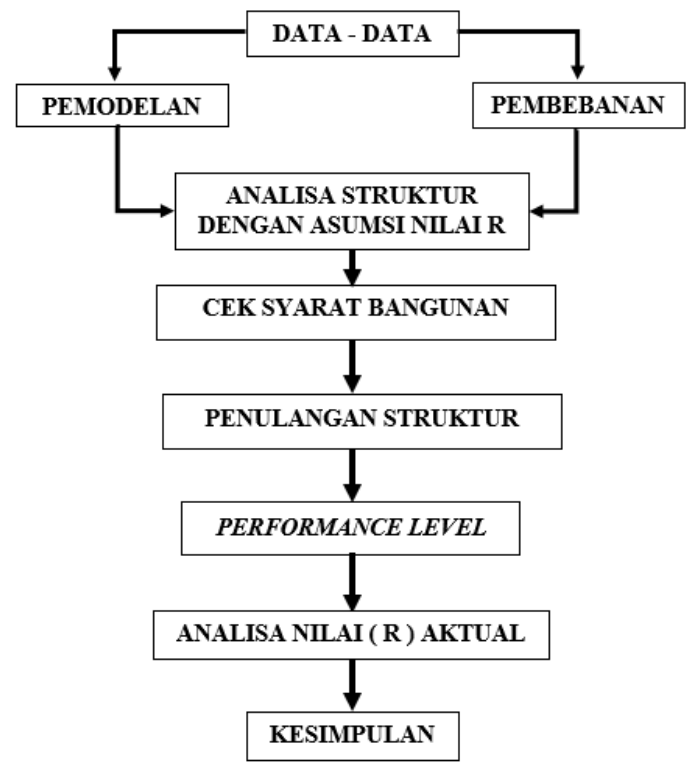

Gambar 1. Alur Penelitian 


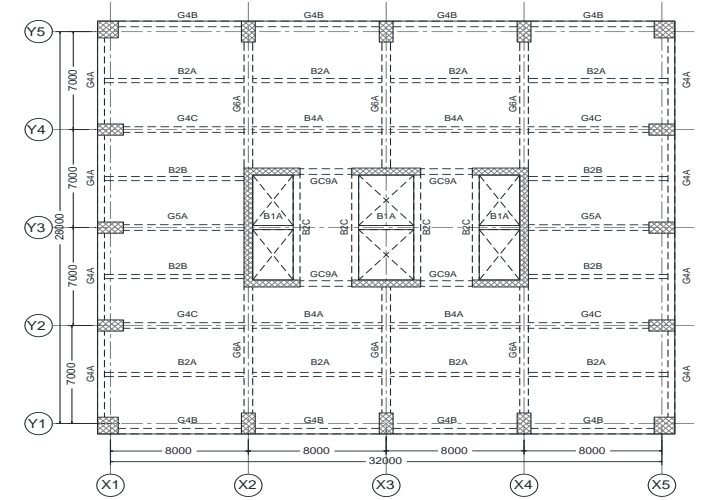

(a)

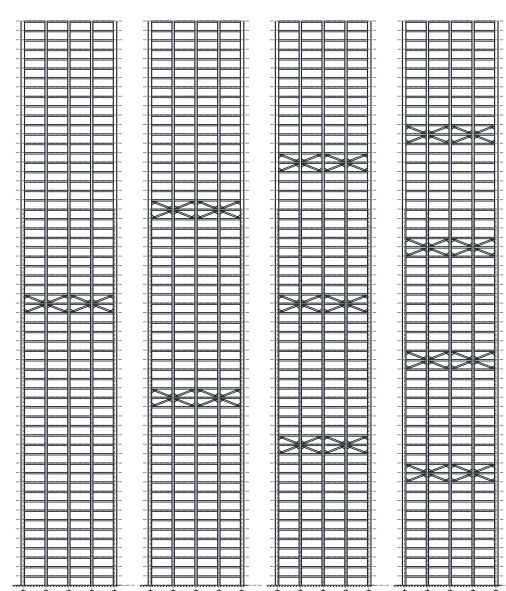

(b)

Gambar 2. (a) Denah Bangunan, (b) Lokasi Belt Truss

\section{HASIL DAN PEMBAHASAN}

\section{Interstory Drift}

Analisis dalam penelitian ini untuk mendapatkan level kinerja dan parameter perencanaan struktur tahan gempa. pada analisa level kinerja hanya dilakukan pada struktur dengan jumlah Belt Truss 2 buah, 3 buah, dan 4 buah. Di karenakan pada struktur dengan menggunakan 1 buah Belt Truss masih terjadi over stress pada struktur. Setelah dilakukan analisa struktur dual system dengan Belt Truss pada Gambar 3 dapat dilihat bahwa interstory drift pada bangunan yang menggunakan Belt Truss terjadi reduksi pada lokas Belt Truss daripada struktur yang hanya menggunakan dual system $(D S)$.

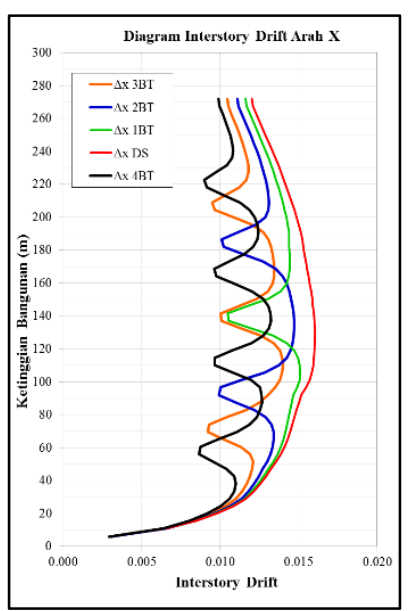

(a)

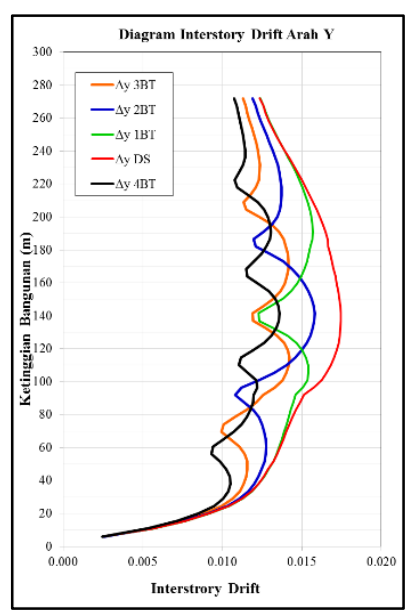

(b)

Gambar 3. Diagram Interstory Drift, (a) Arah X dan (b) Arah Y

\section{Level Kinerja Struktur ATC - 40}

Analisa Kinerja Struktur berdasarkan ATC - 40 dengan menggunakan metode B. hasil dari analisa level kinerja ATC - 40 dapat dilihat pada Gambar 4 sampai Gambar 6. Berdasarkan gambar 4 sampai Gambar 6 menunjukkan bahwa level kinerja struktur Belt Truss adalah Immediate Occupancy $(I O)$. 


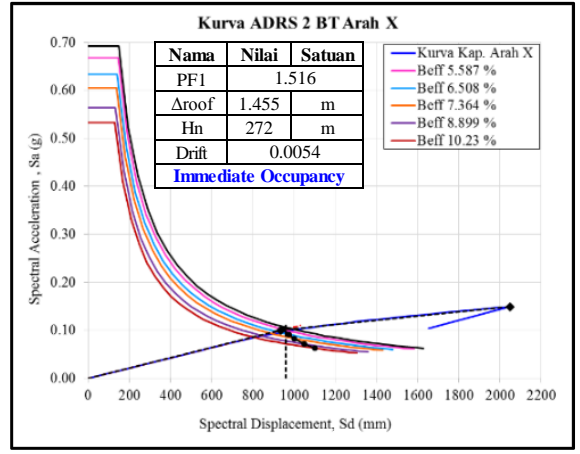

(a)

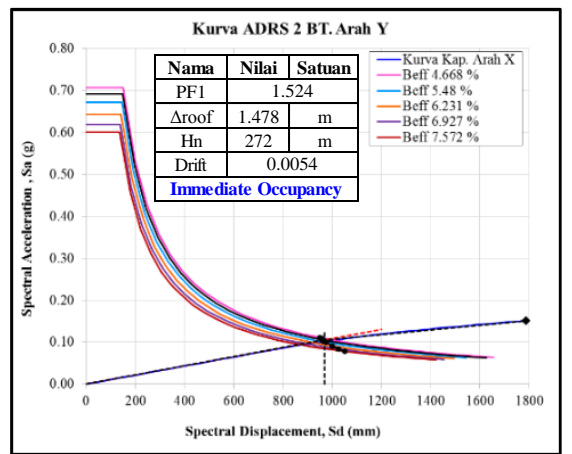

(b)

Gambar 4. Level Kinerja ATC - 40 Struktur 2 BT, (a) Arah X dan (b) Arah Y

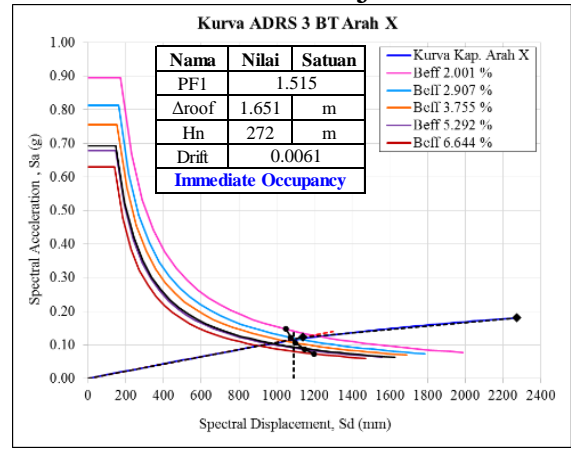

(a)

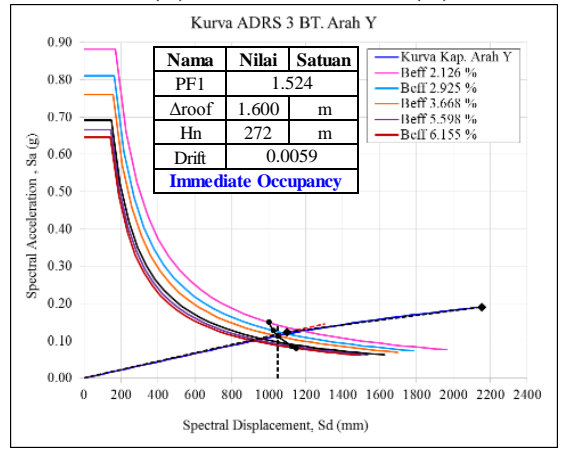

(b)

Gambar 5. Level Kinerja ATC - 40 Struktur 3 BT, (a) Arah X dan (b) Arah Y

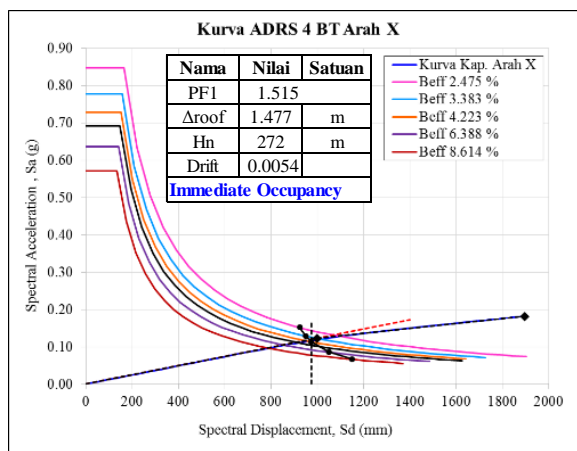

(a)

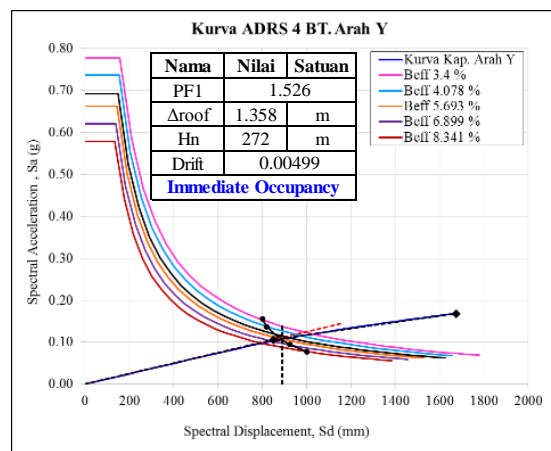

(b)

Gambar 6. Level Kinerja ATC - 40 Struktur 4 BT, (a) Arah X dan (b) Arah Y

\section{Level Kinerja Struktur FEMA 356}

Analisa Kinerja Struktur berdasarkan FEMA 356 dengan menggunakan metode Target Displacement. hasil dari analisa level kinerja FEMA 356 dapat dilihat pada Gambar 7 sampai Gambar 9. Berdasarkan gambar 7 sampai Gambar 9 menunjukkan bahwa level kinerja struktur Belt Truss adalah Immediate Occupancy (IO). 


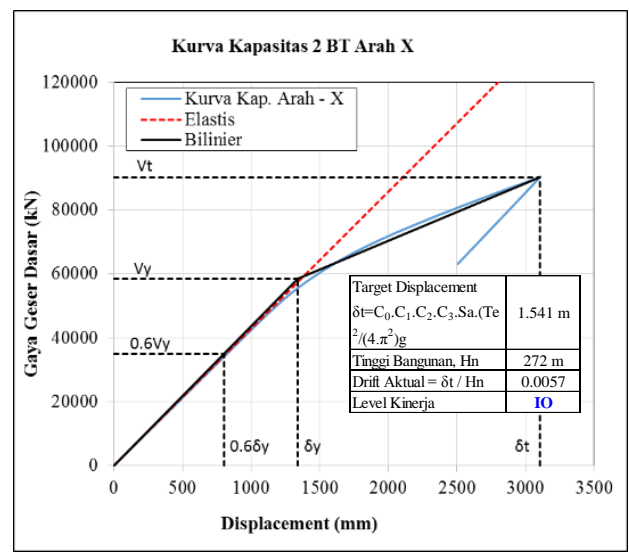

(a)

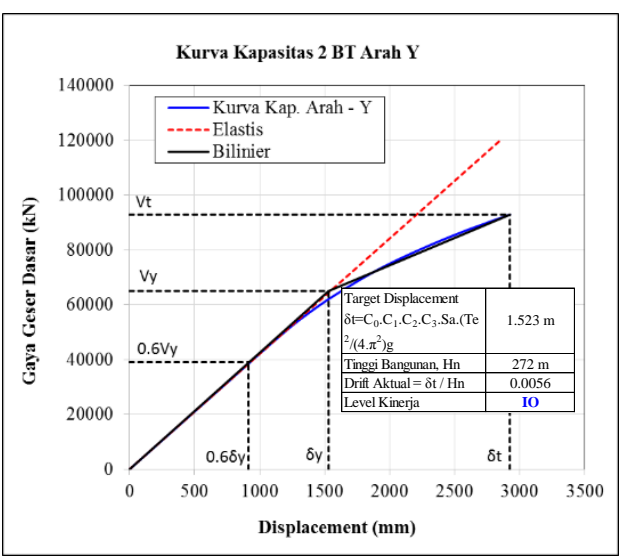

(b)

Gambar 7. Level Kinerja FEMA 356 Struktur 2 BT, (a) Arah X dan (b) Arah Y

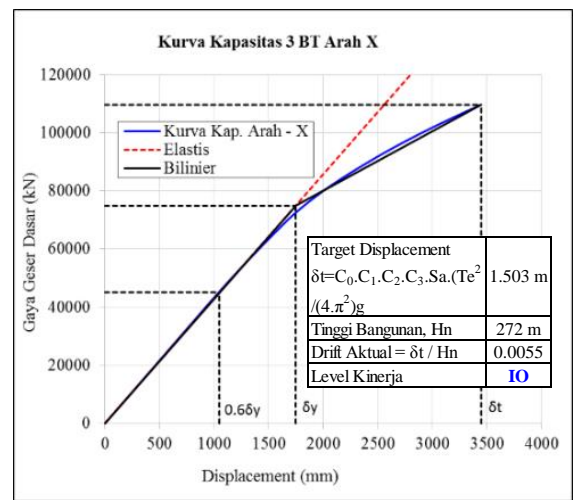

(a)

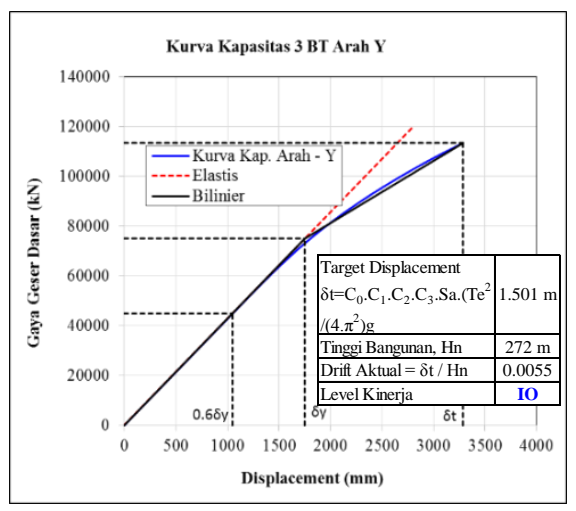

(b)

Gambar 8. Level Kinerja FEMA 356 Struktur 3 BT, (a) Arah X dan (b) Arah Y

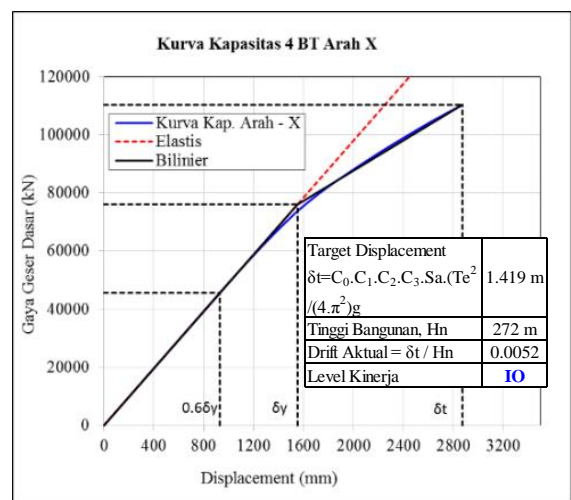

(a)

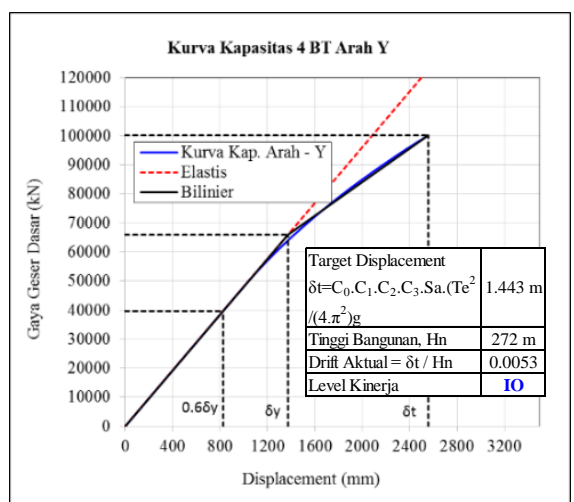

(b)

Gambar 9. Level Kinerja FEMA 356 Struktur 4 BT, (a) Arah X dan (b) Arah Y

\section{Parameter Struktur Tahan Gempa}

Analisa Parameter Struktur Tahan Gempa berdasarkan ASCE 7-16M dengan menggunakan metode Equal Displacement. Hasil dari analisa Parameter Struktur Tahan Gempa ASCE 7-16M dapat dilihat pada Gambar 9 sampai Gambar 12. Berdasarkan gambar 9 sampai Gambar 12 menunjukkan bahwa nilai faktor reduksi respons (R) aktual bernilai 4,5 - 5,0, faktor perbesaran defleksi (Cd) aktual bernilai 5,0 - 6,0 dan faktor kuat lebih $(\Omega 0)$ aktual bernilai 3,0 - 4,0. 


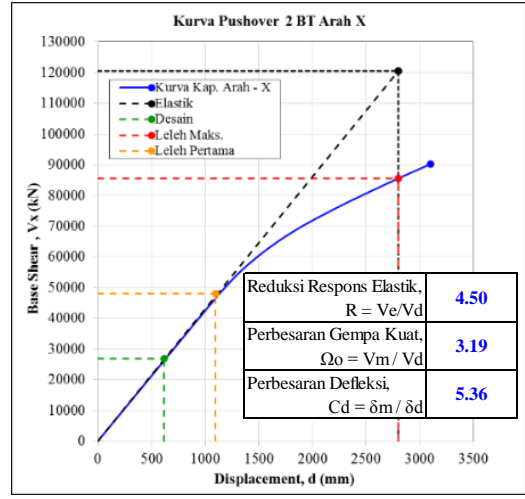

(a)

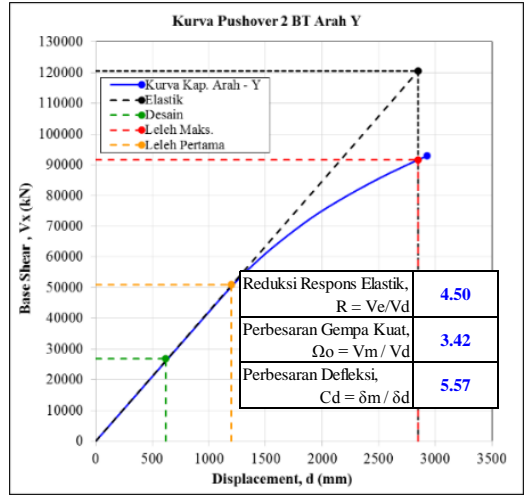

(b)

Gambar 10. Parameter Struktur Tahan Gempa 2 BT, (a) Arah X dan (b) Arah Y

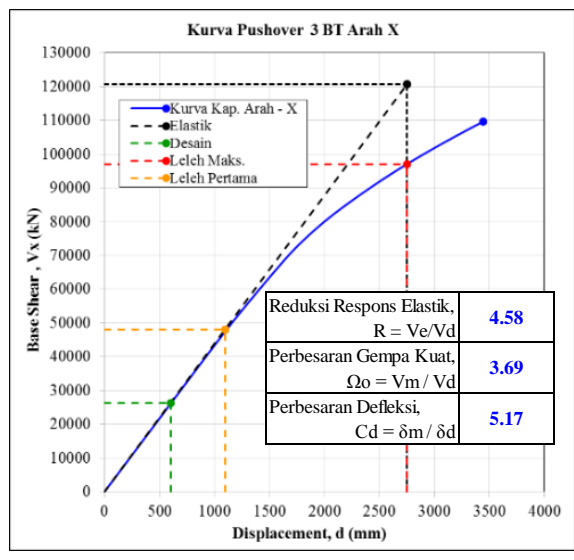

(a)

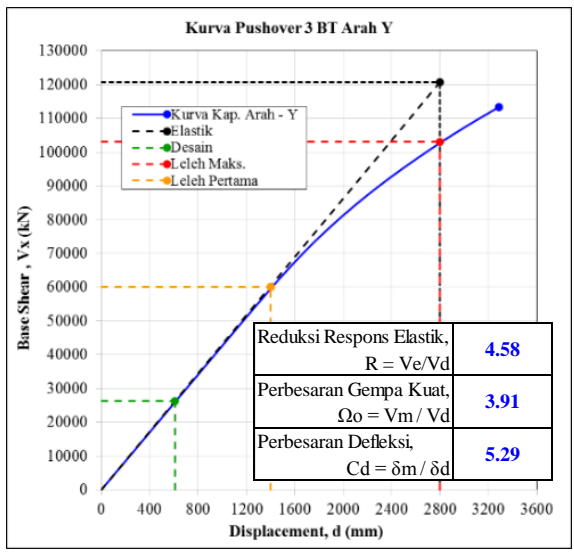

(b)

Gambar 11. Parameter Struktur Tahan Gempa 3 BT, (a) Arah X dan (b) Arah Y

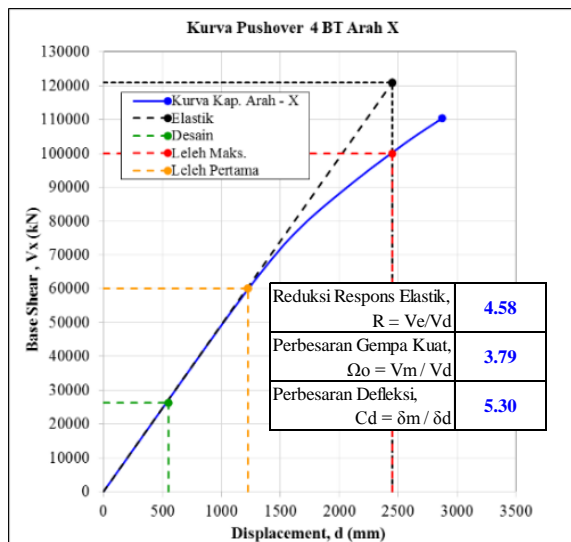

(a)

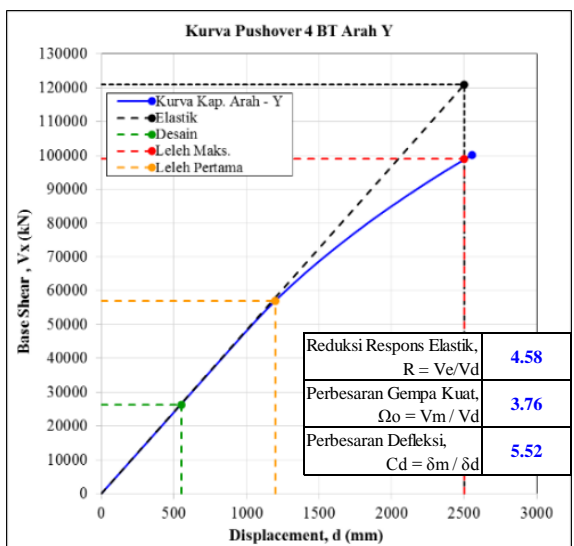

(b)

Gambar 12. Parameter Struktur Tahan Gempa 4 BT, (a) Arah X dan (b) Arah Y

\section{KESIMPULAN}

Berdasarkan hasil analisis evaluasi kinerja (ATC - 40 dan FEMA 356) dan analisa parameter bangunan tahan gempa (ASCE 7-16M), dapat diambil kesimpulan sebagai berikut:

- Level kinerja struktur dual system dengan Belt Truss mempunyai level kinerja Immediate Occupancy karena total drift bangunan tereduksi akibat penambahan struktur Belt Truss.

- $\quad$ Faktor Reduksi Respons Struktur(R) bernilai antara 4,5-5,0.

- Faktor Perbesaran Defleksi (Cd) bernilai 5,0 - 6,0

- $\quad$ Faktor Kuat Lebih Struktur $(\Omega 0)$ bernilai 3,0 - 4,0 


\section{REFERENSI}

ACI 318-14. (2015). "Building Code Requirements for Structural Concrete (ACI318-14) and Comentary (ACI 318RM-14)”. Farminton Hills : American Concrete Institute.

ASCE/SEI 7-16. (2017). "Minimum Design Loads and Associated Criteria for Buildings and Other Structures". Reston, Virginia : American Society of Civil Engineers.

ATC-40. (1996). "Seismik Evaluation And Retrofit Of Concrete Buildings". Redwood City, California, Usa:Applied Technology Council.

Fawzia, S. and Fatima, T. (2010). "Deflection Control in Composite Building by Using Belt Truss and Outriggers Systems". World Academy of Science, Engineering and Technology. International Journal of Structural and Construction Engineering Vol:4, No:12,1010.

Faimun, T., dan Fauzan, K.. (2017). 'Desain Modifikasi Struktur Gedung Apartemen Gunawangsa Tidar Surabaya Menggunakan Struktur Beton Bertulang dengan Sistem Outrigger dan Belt Truss”. Jurnal Teknik ITS Vol. 6, No. 2 (2017) ISSN:2337-3539.

FEMA 356. (2000). "Prestandard And Commentary For The Seismic Rehabilitation Of Buildings”. Washington, D.C. : Federal Emergency Management Agency

Mistry K.Z, Dhyani D.J, (2015) “Optimum Outrigger Location in Outrigger Structural System For High Rise Building", International Journal of Advance Engineering and Research Development (IJAERD) Volume 2, Issue 5, May 2015

Nair R. S. (1998). "Belt Trusses and Basements as Virtual Outrigger for Tall Buildings", Engineering Journal, AISC, Fourth Quarter/1998, pp. 140-146.

Syahriar, Y., Mukarrom, M., Iranata, D., and Adi, T. W., (2012). "Analisis Perbandingan Efektifitas Struktur Gedung dengan Menggunakan Shear Wall dan Kombinasi Antara Shearwall-Outrigger". J. POMITS, vol. 1, no. 1, 2012. 
EVALUASI KINERJA STRUKTUR

DUAL SYSTEM DENGAN BELT TRUSS

Dwi Prasetyo Utomo, et. al.

(halaman ini sengaja dikosongkan) 